\title{
Long Term Effects of Tear Gases on Respiratory System: Analysis of 93 Cases
}

\author{
Peri Arbak, ${ }^{1}$ İlknur Başer, ${ }^{2}$ Özlem Ozdemir Kumbasar, ${ }^{3}$ Füsun Ülger, \\ Zeki Kılıçaslan, ${ }^{5}$ and Fatma Evyapan ${ }^{6}$ \\ ${ }^{1}$ Department of Chest Diseases, Duzce University Medical Faculty, Düzce, Turkey \\ ${ }^{2}$ Emergency Department, Ankara Numune State Hospital, Ankara, Turkey \\ ${ }^{3}$ Department of Chest Diseases, Ankara University Medical Faculty, Ankara, Turkey \\ ${ }^{4}$ Department of Chest Disease, Private Practice, Ankara, Turkey \\ ${ }^{5}$ Department of Chest Diseases, Istanbul University Medical Faculty, Istanbul, Turkey \\ ${ }^{6}$ Department of Chest Diseases, Pamukkale University Medical Faculty, Denizli, Turkey
}

Correspondence should be addressed to Peri Arbak; periarbak@hotmail.com

Received 22 April 2014; Revised 20 June 2014; Accepted 1 July 2014; Published 22 July 2014

Academic Editor: Shuguang Leng

Copyright (C) 2014 Peri Arbak et al. This is an open access article distributed under the Creative Commons Attribution License, which permits unrestricted use, distribution, and reproduction in any medium, provided the original work is properly cited.

Aim. This study aimed to assess the long-term respiratory effects of tear gases among the subjects with history of frequent exposure. Materials and Methods. A questionnaire by NIOSH and pulmonary function tests was performed in 93 males exposed to the tear gases frequently and 55 nonexposed subjects. Results. The mean numbers of total exposure and last 2 years exposure were $8.4 \pm 6.4$ times, $5.6 \pm 5.8$ times, respectively. Tear gas exposed subjects were presented with a higher rate for cough and phlegm more than 3 months $(24.7 \%$ versus $11.3 \%, P>0.05)$. Mean FEV1/FVC and \% predicted MMFR in smoker exposed subjects are significantly lower than those in smoker controls ( $81.7 \%$ versus $84.1 \%, P=0.046$ and $89.9 \%$ versus $109.6 \%, P=0.0004$, resp.). \% predicted MMFR in nonsmoker exposed subjects is significantly lower than that in nonsmoker controls (99.4\% versus $113.1 \%, P=0.05)$. Odds ratios for chest tightness, exercise dyspnea, dyspnea on level ground, winter morning cough, phlegm, and daily phlegm were increased almost 2 to 2.5 folds among tear gas exposed subjects. Conclusion. The rates for respiratory complaints were high in the case of the exposure to the tear gases previously. Tears gas exposed subjects were found to be under the risk for chronic bronchitis.

\section{Introduction}

Tear gases have been used as "Riot Control Agents" for a long time by police forces. The mostly used agents among tear gases are 2-chlorobenzylidene malononitrile (CS), oleoresincapsicum $(\mathrm{OC})$, and chloroacetophenone $(\mathrm{CN})[1,2]$. The usage types of tear gases are gas bomb and spray. The main effect of "Riot Control Agents" is irritation of mucosal surfaces.

Respiratory symptoms related to CS are nasal irritation, rhinorrhea, cough, and breathlessness. Although the respiratory symptoms are transient in nature, laryngospasm, pulmonary edema, and reactive airways dysfunction have also been reported $[3,4]$. Exposure in closed spaces increases the detrimental effects of CS. Pulmonary function deterioration and respiratory complaints might be observed several months after the cessation of exposure to CS [1]. Karagama et al. reported that out of 34 persons exposed to CS in a closed area 23 had respiratory complaints after one hour after the cessation of exposure. They followed the cases and showed that respiratory symptoms persisted for 10 months in 5 subjects [5].

Other common tear gas, OC, may also cause sore throat, cough, wheezing, shortness in breath, laryngospasm, and rarely respiratory arrest [6]. Steffee et al. investigated custodydeaths related to pepper spray. In that report, the victim was an asthmatic who had been sprayed 10 to 15 times with pepper spray. Postmortem examination revealed severe 
epithelial lung damage, and the cause of death was severe acute bronchospasm, probably precipitated by the use of pepper spray.

In the last few years, the inappropriate use of "Riot Control Agents" has been a public concern in Turkey. Turkish Police Department declared that they mostly used OC and CS as tear gases for controlling protest actions. Some tear gas related deaths have been reported. Turkish Medical Association attempted to forbid the use of tear gases since those turned out to be a huge public health problem [7].

Turkish Thoracic Society has faced tremendous amount of questions about tear gases since last years. The aim of this study was to compare the respiratory complaints and pulmonary functions of 93 subjects who were frequently exposed to tear gases and 55 nonexposed subjects as a control group.

\section{Materials and Methods}

This study was conducted between March 2012 and October 2012. White collar workers, teachers, students, journalists, professional unionists, and political activists with frequent exposure were enrolled into the study group (total 93 subjects). All were men and were exposed to the tear gases much more frequently compared to general population. Fifty-five nonexposed subjects-health care workers, bureau workers, and faculty members-matched for age, gender, and smoking status formed the control group. We used a questionnaire about exposure (the total number of exposure times for last 2 years, the type of tear gases, and distance from the source), hospitalization after the exposure, and selfprevention measures against exposure. We also used an additional questionnaire, Initial Questionnaire of the NIOSHOccupational Asthma Identification Project. We performed pulmonary function tests with same equipment (Vitalograph Alpha) and the same subject (PA) according to ATS criteria [8]. Spirometry measurements-forced vital capacity (FVC) and forced expiratory volume in $1 \mathrm{~s}$ (FEV1) and maximal midexpiratory flow rate (MMFR) - are used as percent of predicted values.

Spirometric measurements and questionnaires were done in the centre of United Metalworkers' Union, İstanbul, the center of Confederation of Public Workers' Unions, Ankara, and Duzce University, Medical Faculty, Department of Pulmonary Disease, Duzce.

An ethical approvement was obtained from Ethical Committee of Istanbul University.

SPSS-13.0 statistical programme was used. The Chisquare test was used for testing differences in the prevalence of respiratory symptoms, other symptoms, smoking status, and asthma history among the groups. Odds ratios for the presence of respiratory symptoms were calculated in the case of the exposure to tear gases. Comparison of spirometric measurements was performed by $t$-test for two independent samples. A $P$ value less than 0.05 was considered as statistically significant.
TABLE 1: Demographic and health aspects of exposed subjects and controls.

\begin{tabular}{lccc}
\hline & $\begin{array}{c}\text { Exposed subjects } \\
n=93\end{array}$ & Controls $n=55$ & $P$ \\
\hline Age (years) & $38.9 \pm 9.3$ & $36.3 \pm 8.6$ & $>0.05$ \\
Height $(\mathrm{cm})$ & $175.4 \pm 7.4$ & $175.9 \pm 6.3$ & $>0.05$ \\
Weight $(\mathrm{kg})$ & $81.3 \pm 14.3$ & $81.4 \pm 12.2$ & $>0.05$ \\
Smokers & $70(75.3 \%)$ & $35(66.0 \%)$ & $>0.05$ \\
Subjects with & $7(7.5 \%)$ & $5(9.4 \%)$ & $>0.05$ \\
asthma history & & & \\
\hline
\end{tabular}

TABLE 2: Respiratory complaints of subjects.

\begin{tabular}{lccc}
\hline & $\begin{array}{c}\text { Exposed subjects } \\
n=93\end{array}$ & $\begin{array}{c}\text { Controls } \\
n=55\end{array}$ & $P$ \\
\hline Wheezing & $56(60.2 \%)$ & $24(45.3 \%)$ & $>0.05$ \\
Dyspnea last year & $41(44.1 \%)$ & $15(28.3 \%)$ & 0.043 \\
Chest tightness last year & $35(37.6 \%)$ & $8(15.2 \%)$ & 0.003 \\
Exercise dyspnea last year & $40(43.0 \%)$ & $12(22.6 \%)$ & 0.010 \\
Dyspnea on level ground & $59(63.4 \%)$ & $17(32.1 \%)$ & 0.0002 \\
Winter morning cough & $30(32.3 \%)$ & $7(13.2 \%)$ & 0.008 \\
Winter daily cough & $36(38.7 \%)$ & $12(22.6 \%)$ & 0.034 \\
Cough for 3 months & $25(26.9 \%)$ & $8(15.1 \%)$ & $>0.05$ \\
Winter morning phlegm & $26(28.0 \%)$ & $6(11.3 \%)$ & 0.014 \\
Winter daily phlegm & $39(41.9 \%)$ & $11(20.8 \%)$ & 0.007 \\
Phlegm for 3 months & $24(25.8 \%)$ & $6(11.3 \%)$ & 0.028 \\
\hline
\end{tabular}

\section{Results}

Demographic and health aspects of exposed subjects and controls are shown in Table 1.

The mean number of total exposure times (life-long exposure) to tear gases was $8.4 \pm 6.4$ times (min: 1 , max: 30 ) and the mean number of the last 2 years exposure times was $5.6 \pm 5.8$ times (min: 1 , max: 40).

The mean daily cigarette consumption among exposed subjects $(22.5 \pm 12.1)$ was significantly higher than that in controls $(15.2 \pm 7.7, P=0.003)$.

The mean beginning age (years) of smoking among exposed subjects $(18.5 \pm 4.8)$ was not different than that in controls $(18.7 \pm 5.0, P>0.05)$.

Respiratory complaints of subjects are shown in Table 2.

Exposed subjects have had higher respiratory complaints rates except wheezing and cough for 3 months than controls.

The incidence of both cough and phlegm complaints more than 3 months is seen in Figure 1.

Tear gas exposed subjects were presented with a higher rate for cough and phlegm of more than 3 months $(P>0.05)$.

The rates for runny nose, watery eyes, and dermatitis during the last 12 months are shown in Figure 2.

Higher rates for runny nose, watery eyes, and dermatitis were seen among tear gas exposed subjects compared to nonexposed ones but the differences were not statistically significant.

Pulmonary function data of subjects are shown in Table 3. 


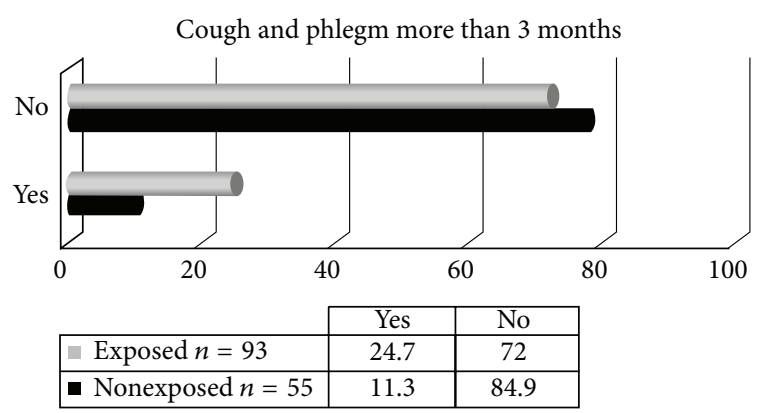

FIGURE 1: Cough and phlegm more than 3 months among subjects.

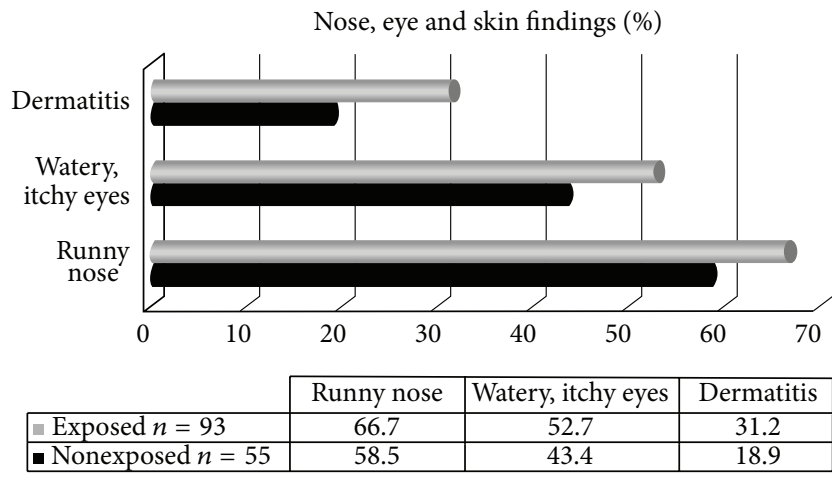

Figure 2: Nose, eye, and skin complaints among tear gas exposers.

TABLE 3: Pulmonary functions of subjects.

\begin{tabular}{lccc}
\hline \% predicted & $\begin{array}{c}\text { Exposed subjects } \\
n=93 \\
(\text { smokers }=70)\end{array}$ & $\begin{array}{c}\text { Controls } n=55 \\
(\text { smokers }=35)\end{array}$ & $P$ \\
\hline FVC & $97.3 \pm 11.9$ & $89.9 \pm 11.7$ & 0.0003 \\
Smokers FVC & $97.3 \pm 11.9$ & $91.2 \pm 12.2$ & 0.018 \\
Nonsmokers FVC & $97.4 \pm 12.0$ & $87.8 \pm 11.1$ & 0.013 \\
FEV1 & $96.9 \pm 12.9$ & $95.9 \pm 12.0$ & $>0.05$ \\
Smokers FEV1 & $96.0 \pm 13.1$ & $96.8 \pm 13.7$ & $>0.05$ \\
Nonsmokers FEV1 & $99.5 \pm 12.1$ & $94.6 \pm 8.9$ & $>0.05$ \\
FEV1/FVC & $82.4 \pm 6.9$ & $84.2 \pm 4.7$ & $>0.05$ \\
Smokers & $81.7 \pm 7.4$ & $84.1 \pm 4.6$ & 0.046 \\
Nonsmokers & $84.3 \pm 5.1$ & $84.4 \pm 5.3$ & $>0.05$ \\
MMFR & $92.3 \pm 25.1$ & $110.4 \pm 24.5$ & $<0.001$ \\
Smokers MMFR & $89.9 \pm 25.9$ & $109.6 \pm 26.8$ & 0.0004 \\
Nonsmokers MMFR & $99.4 \pm 21.5$ & $113.1 \pm 21.3$ & 0.05 \\
\hline
\end{tabular}

Mean FEV1/FVC and \% predicted MMFR in smoker exposed subjects are significantly lower than those in smoker controls $(P=0.046$ and $P=0.0004$, resp.). \% predicted MMFR in nonsmoker exposed subjects is significantly lower than that in nonsmoker controls $(P=0.05)$.

Odds ratios of respiratory complaints for tear gas exposed group are shown in Table 4.
TABLE 4: Odds ratios of respiratory complaints in tear gas exposed group.

\begin{tabular}{lccc}
\hline Parameter & Odds ratio & \multicolumn{2}{c}{ 95\% confidence interval } \\
\hline Chest tightness last year & 2.493 & 1.251 & 4.971 \\
Exercise dyspnea last year & 1.900 & 1.096 & 3.292 \\
Dyspnea on level ground & 1.978 & 1.298 & 3.013 \\
Winter morning cough & 2.442 & 1.153 & 5.172 \\
Winter morning phlegm & 2.470 & 1.086 & 5.613 \\
Winter daily phlegm & 2.021 & 1.134 & 3.601 \\
\hline
\end{tabular}

\section{Discussion}

Current study showed marked increase in respiratory complaints including cough, phlegm, dyspnea, and chest tightness among subjects frequently exposed to tear gases compared to nonexposed subjects since last year. A significant decrease in the mean \% predicted maximal expiratory flow rate in tear gas exposed subjects was detected and both of the mean \% predicted maximal expiratory flow rate and FEV1/FVC ratio significantly decreased among cigarette smokers.

Previous studies have focused on the acute effects of tear gases and most of them are based on experimental studies of voluntary subjects in the laboratory basis. In the case of the exposure to OC, transient respiratory complaints that ranged from coughing and shortness of breath to gasping for breath were linked to the inflammation and irritation. Authors also reported excess nasal and tracheobronchial secretions, sneezing, and changes in breathing pattern [9-11]. Studies focused on the chronic effects of OC are scarce and most of them are associated with occupational exposure to capsaicinoids. These studies typically reported initial respiratory symptoms similar to those seen with acute exposure (e.g., cough, runny nose, and sneezing). As seen in byssinosis these symptoms decreased and often were completely reversed, with continued exposure. In a study including 22 hot pepper workers with chronic exposure to hot chili powder showed chronic cough in $59 \%$ of the exposed workers, compared to $21 \%$ of the controls. The exposed workers also had more common complaints of chest discomfort, shortness of breath, and stuffy or runny nose [12]. Another study showed increased respiratory symptoms (upper respiratory tract irritation, sneezing, and runny nose) in $49 \%$ of male spice grinders related to workplace exposure [13]. Morning cough $(32 \%)$ and daily cough during winter $(39 \%)$ were high; furthermore morning phlegm $(28.0 \%)$, daily phlegm in winter $(42.0 \%)$, and phlegm more than 3 months (26\%) were accompanying to cough among tear gas exposed subjects in the present study. It has been postulated that the lesser exposure to capsaicinoids during protest actions than that in spice processing and exposure to tear gases at the outdoors led to a lower chronic cough rate. Tear gas exposed subjects also presented high rates of dyspnea (44\%), chest tightness (37.6\%), and exercise dyspnea in the last year (43\%). Comparably to the spice workers, OC exposed subjects have had high rates for irritation symptoms such as runny nose $(66.7 \%)$, watery eyes $(52.7 \%)$, and dermatitis $(31.2 \%)$. The results of tear gas exposed subjects were similar to those in 
two studies that evaluated the long term respiratory effects in the case of the exposure to sulfur mustard [14]. A study of 197 Iranian veterans, 10 years after a single heavy exposure to sulfur mustard, revealed a series of delayed destructive pulmonary sequela such as chronic bronchitis (58\%), asthma (10\%), bronchiectasis (8\%), large airway narrowing (9\%), and pulmonary fibrosis (12\%) [14]. Sixteen to twenty years after exposure, main respiratory complications were diagnosed as chronic obstructive pulmonary disease (35\%), bronchiectasis (32.5\%), asthma (25\%), large airway narrowing (15\%), pulmonary fibrosis $(7.5 \%)$, and simple chronic bronchitis (5\%) [15]. Cough and phlegm more than 3 months incidence was $24.7 \%$ in the present study. In a review by $\mathrm{Hu}$ et al., in the case of pure CS exposure, shopkeepers and their families in communities nearby where the demonstrations took place complained of cough and shortness of breath that persisted for several weeks after political demonstrations in Seoul, July 1989 [1]. Coughing, wheezing, and dyspnea persisted for two years after short term exposure to CS in a previously well 21-year-old woman [4]. Among 34 young adults exposed to CS in a coach, 5 of them had respiratory symptoms, 2 had worsening of asthma, 2 had decreased exercise tolerance, and 1 complained of coughing fits after exercise at the examination done 8 to 10 months after the exposure [5]. Respiratory complaint rates between $26 \%$ and $44 \%$ among subjects exposed to tear gases in a regular basis (mean lifelong exposure number 8.4 and the mean last 2 years exposure number 5.6) were compatible with the knowledge on the long term effects of CS in the literature.

There is little knowledge on the long term effects of capsaicinoids on pulmonary functions and most of them are based on occupational exposure. A study of 22 hot pepper workers chronically exposed to hot chili powder and 19 unexposed workers in the same plant showed no significant decrease in baseline pulmonary function in exposed group. History of asthma did not affect pulmonary function tests [12]. In another study, Lankatilake and Uragoda evaluated pulmonary function in 25 male workers of chili grinding factories in Sri Lanka with an average of 6.6 years of exposure. Pulmonary function measurements in the exposed workers were not different from the controls, and there was no difference between the pre- and postshift pulmonary function measurements in exposed workers after a weekend of no exposure [16]. The mean FEV1/FVC ratio of tear gas exposed and smoker subjects was lower than that of exposed ones in the present study. Furthermore significant decreases in mean \% predicted MMFRs of both smoker and nonsmoker tear gas exposed subjects showed an obstructive pattern in pulmonary function. The additive mixtures used in $\mathrm{OC}$ and CS, exposure to both OC and CS during protest actions, and massive use of tear gases may be responsible for marked decrease in MMFR among tear gas exposed subjects. Present study is the unique one for reflecting the long term respiratory health consequences of subjects faced with tear gases in real life such as protest actions. Limited reliability of the knowledge on the exposure to tear gases is one of the limitations of the present study. Lack of the memory when answering the questionnaire by NIOSH is the second one. At least two types of tear gases (OC and CS) and their additives effects on the respiratory system have been evaluated and none of them have not been incriminated for the obstructive pattern alone.

In the light of the results in the present study, consider the following.

(i) Being exposed to tear gases decreases maximal mid expiratory flows in both smokers and nonsmokers.

(ii) Being both smoker and exposed to tear gases decreases FEV1/FVC ratio.

(iii) Chronic bronchitis is increased among exposed subjects although this rate does not reach statistical significance.

(iv) Almost all of the complaints related to the upper and lower respiratory tract, eyes, and skin increase in the case of the exposure to the tear gases.

Additional efforts are necessary for searching the hazardous effects of tear gases to be able to forbid the use of tear gases as for controlling the protest actions.

\section{Conflict of Interests}

The authors declare that there is no conflict of interests regarding the publication of this paper.

\section{Acknowledgments}

The authors would like to thank Ozgur Bozdogan and the subjects who participated in this study by sharing their valuable time and efforts. This study is a project by Turkish Thoracic Society.

\section{References}

[1] H. Hu, J. Fine, P. Epstein, K. Kelsey, P. Reynolds, and B. Walker, "Tear gas-harassing agent or toxic chemical weapon?" Journal of the American Medical Association, vol. 262, no. 5, pp. 660663, 1989.

[2] C. G. Smith and W. Stopford, "Health hazards of pepper spray," North Carolina medical journal, vol. 60, no. 5, pp. 268-274, 1999.

[3] S. Park and S. T. Giammona, "Toxic effects of tear gas on an infant following prolonged exposure," The American Journal of Diseases of Children, vol. 123, no. 3, pp. 245-246, 1972.

[4] H. Hu and D. Christiani, "Reactive airways dysfunction after exposure to teargas," The Lancet, vol. 339, no. 8808, p. 1535, 1992.

[5] Y. G. Karagama, J. R. Newton, and C. J. R. Newbegin, "Shortterm and long-term physical effects of exposure to CS spray," Journal of the Royal Society of Medicine, vol. 96, no. 4, pp. 172174, 2003.

[6] C. H. Steffee, P. E. Lantz, L. M. Flannagan, R. L. Thompson, and D. R. Jason, "Oleoresin capsicum (pepper) spray and "incustody deaths'”, The American Journal of Forensic Medicine and Pathology, vol. 16, no. 3, pp. 185-192, 1995.

[7] T. Tabipleri Birliği, Kimyasal Silahlar Gösteri Kontrol Ajanları. Birinci Baskı, Ağustos 2011, Ankara Türk Tabipleri Birliği Yayınları.

[8] "Standardization of spirometry, 1994 update. American Thoracic Society," American Journal of Respiratory and Critical Care Medicine, vol. 152, no. 3, pp. 1107-1136, 1995. 
[9] B. Ballantyne, "Peripheral sensory irritation: basics and applications," in General and Applied Toxicology, B. Ballantyne, T. C. Marrs, and T. Syversen, Eds., vol. 2, pp. 611-630, Macmillan Reference, London, UK, 2nd edition, 1999.

[10] B. Ballantyne, "Peripheral chemosensory irritation with particular reference to respiratory tract exposure," in Inhalation Toxicology, H. Salem and S. Katz, Eds., CRC Press, Boca Raton, Fla, USA, 2nd edition, 2005.

[11] B. Ballantyne and H. Salem, "Forensic aspects of riot control agents," in Riot Control Agents: Issues in Toxicology, Safety, and Health, E. J. Olajos and W. Stopford, Eds., pp. 231-258, CRC Press, Boca Raton, Fla, USA, 2004.

[12] P. Blanc, D. Liu, C. Juarez, and H. A. Boushey, "Cough in hot pepper workers," Chest, vol. 99, no. 1, pp. 27-32, 1991.

[13] O. Y. Chan, C. S. Lee, K. T. Tan, and T. Thirumoorthy, "Health problems among spice grinders," Journal of the Society of Occupational Medicine, vol. 40, no. 3, pp. 111-115, 1990.

[14] A. Emad and G. R. Rezaian, "The diversity of the effects of sulfur mustard gas inhalation on respiratory system 10 years after a single, heavy exposure: analysis of 197 cases," Chest, vol. 112, no. 3, pp. 734-738, 1997.

[15] M. Hefazi, D. Attaran, M. Mahmoudi, and M. Balali-Mood, "Late respiratory complications of mustard gas poisoning in Iranian veterans," Inhalation Toxicology, vol. 17, no. 11, pp. 587592, 2005.

[16] K. N. Lankatilake and C. G. Uragoda, "Respiratory function in chilli grinders," Occupational Medicine, vol. 43, no. 3, pp. 139142, 1993. 


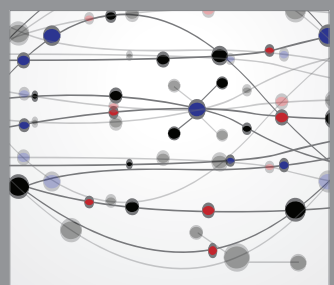

The Scientific World Journal
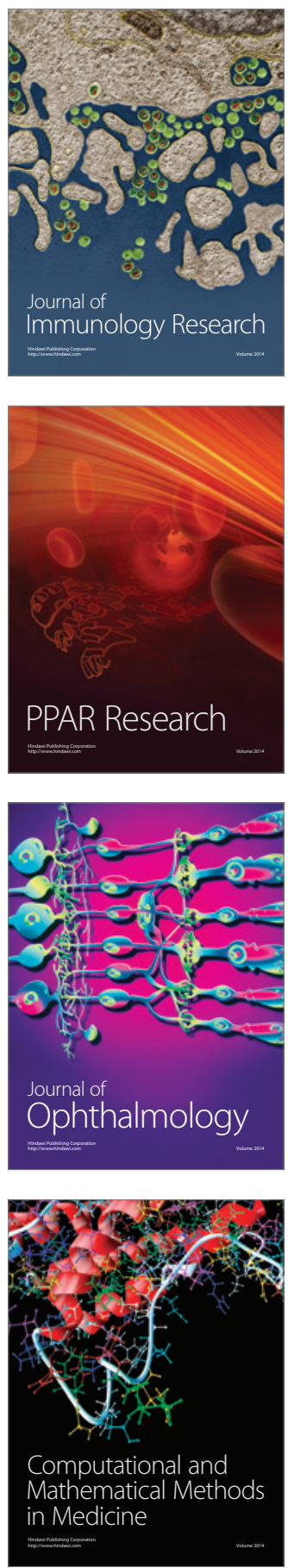

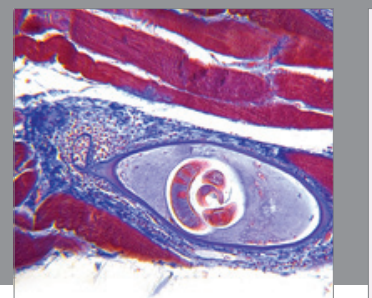

Gastroenterology

Research and Practice
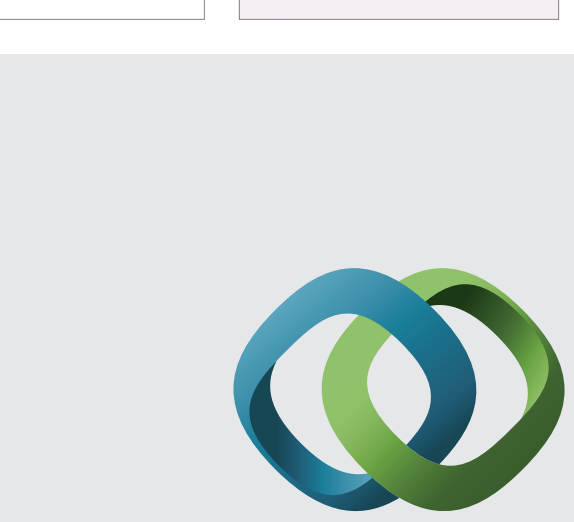

\section{Hindawi}

Submit your manuscripts at

http://www.hindawi.com
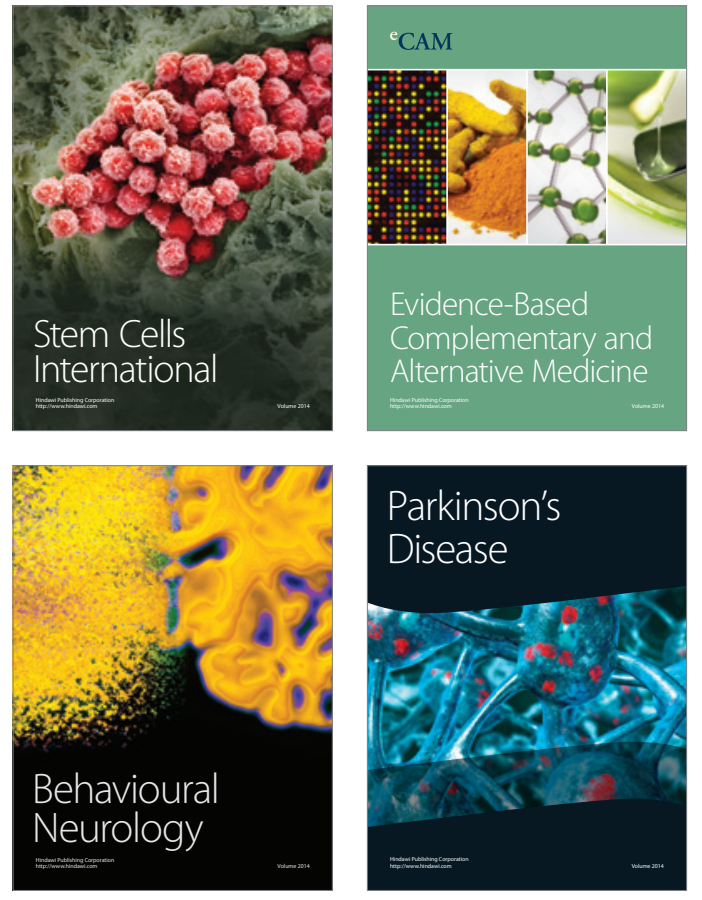
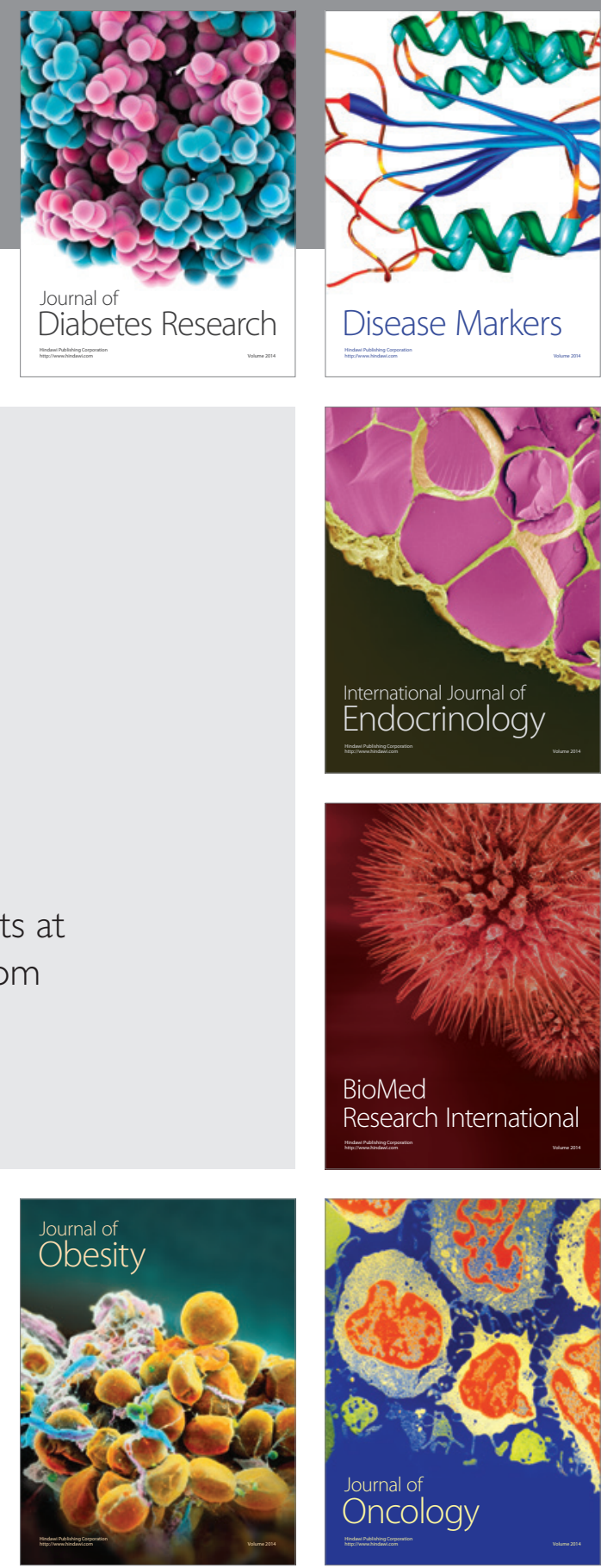

Disease Markers
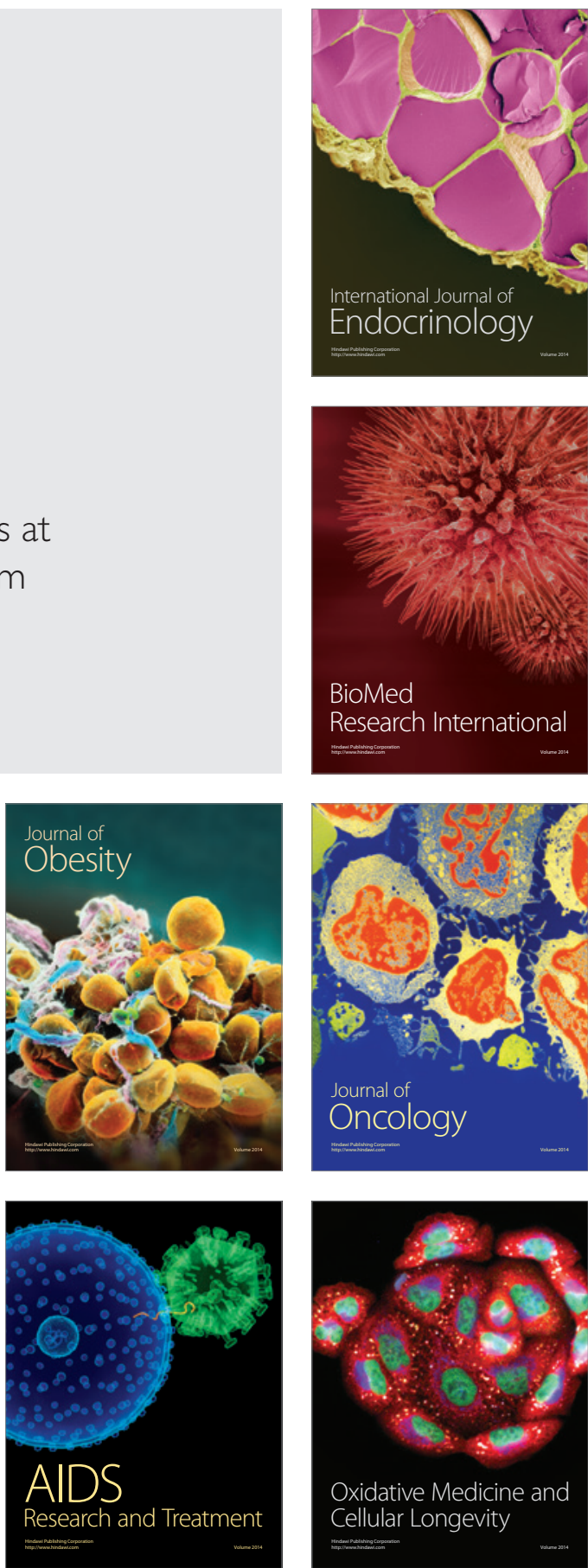